\title{
A matemática presente no dimensionamento de um sistema de tratamento de efluentes domésticos
}

\author{
Márcia Jussara Hepp Rehfeldt \\ Centro Universitário UNIVATES \\ mrehfeld@univates.br
}

\author{
Denner Erthal \\ Centro Universitário UNIVATES \\ denner_erthal@hotmail.com
}

\begin{abstract}
Resumo
Esta proposta de sala de aula tem por intuito discutir alguns conceitos relacionados aos volumes de efluentes armazenados em um sistema de tratamento de esgoto doméstico, composto por fossa, filtro e sumidouro. Embora exista uma normativa acerca do volume mínimo a ser armazenado em cada tanque, em cada cidade, nada consta acerca das dimensões no que diz respeito ao comprimento, largura e altura. Assim, o intuito da prática é discutir as possíveis alterações nestas dimensões dos tanques que armazenam os efluentes. Para a execução da prática, sugerem-se visita a uma obra, conversas com engenheiro responsável e a confecção de maquetes para visualizar o sistema de tratamento. Ainda é possível problematizar os arredondamentos nas dimensões do tanque e as alterações que poderão ocorrer caso o conjunto de tanques seja construído de diferentes formas. Entende-se que esta prática pode promover discussões, correlacionando temáticas de diversas áreas e assim fomentar posicionamentos críticos e reflexivos, desenvolvendo a capacidade de comunicação dos estudantes.
\end{abstract}

Palavras-chave: Geometria. Volume. Sistema de Efluentes. Dimensões.

\section{The mathematics present in the sizing of a domestic effluent treatment system}

\begin{abstract}
This classroom proposal is meant to discuss some concepts related to effluent volumes stored in a domestic sewage treatment system, composed by cesspool, filter and sink. Although there is a rule about the minimum volume to be stored in each tank, in each city, nothing is said about the dimensions with regard to the length, width and height. So, the aim of the practice is to discuss possible alterations in the dimensions of the tanks that stores the effluent. For the execution of the practice, is suggested a visit to a construction work, conversations with the responsible engineer and confection of models to visualize the treatment system. Still, it is possible to discuss the rounding on the dimensions of the tank and the alterations that can occur if the set of tanks is constructed in different ways. It's understood that this practice can promote discussions, correlating various
\end{abstract}


thematic areas and thus foment critical and reflective positions, developing the communication capacities of the students.

Keywords: Geometry. Volume. Effluent system. Dimensions. Standard.

\section{Introdução}

De acordo com os Parâmetros Curriculares Nacionais (BRASIL, 2006, p. 75)

Estudo da Geometria deve possibilitar aos alunos o desenvolvimento da capacidade de resolver problemas práticos do quotidiano, como, por exemplo, orientar-se no espaço, ler mapas, estimar e comparar distâncias percorridas, reconhecer propriedades de formas geométricas básicas, saber usar diferentes unidades de medida. Também é um estudo em que os alunos podem ter uma oportunidade especial, com certeza não a única, de apreciar a faceta da Matemática que trata de teoremas e argumentações dedutivas. Esse estudo apresenta dois aspectos - a geometria que leva à trigonometria e a geometria para o cálculo de comprimentos, áreas e volumes.

No entanto, estudos como os Rabaiolli (2014), Nascimento (2014) e Radaelli (2010) apontam que este tema tem sido pouco desenvolvido nas escolas. Para Pereira (2001) apud Rabaoilli (2014, p. 18), o abandono da geometria se deve a diversos fatores, entre eles a falta de formação de professores nesta área, a "abordagem insuficiente dos livros didáticos e as lacunas deixadas pelo Movimento da Matemática Moderna”.

De acordo com Nascimento (2014, p. 30), a geometria deve ser explorada ao longo do ano e de forma prática, "fazendo com que os alunos construam sólidos, familiarizando-se cada vez mais com seus componentes, chegando ao ponto de, na íntegra, visualizá-la no dia a dia, aplicando o conhecimento de forma consciente". De forma complementar, Rabaiolli (2014) menciona que o estudo da geometria permite uma abordagem crítica da realidade, estabelecendo relações entre os conteúdos estudados pelos alunos e as situações concretas, permitindo assim ao aluno partir de situações concretas para depois abstraí-las.

À luz de alguns referenciais e tomando como ponto de partida uma situaçãoproblema, propõe-se a seguir uma prática de sala de aula. Dependo do nível de escolarização dos alunos, esta atividade poderá ser desenvolvida parcialmente e adaptações à realidade local são recomendadas, pois cidades sem rede de esgoto cloacal têm normativas próprias para o tratamento de esgoto. Os dados aqui utilizados se referem à construção de um sistema de tratamento de efluentes domésticos de uma determinada cidade localizada no interior do Rio Grande do Sul. 


\section{A proposta da prática}

Segundo regulamentação desta Prefeitura Municipal, cada residência necessita construir um sistema de tratamento de efluentes domésticos constituído de fossa séptica, filtro anaeróbio e sumidouro, em alvenaria, para coletar os resíduos sólidos e líquidos, que pode ser conforme ilustrado na Figura 1.

No tanque I observa-se a fossa séptica que coleta diretamente os efluentes domésticos sólidos como os liberados em pias da cozinha e vasos sanitários. Já no tanque II visualiza-se o filtro anaeróbico responsável pela filtração de algumas partículas. Por fim, no tanque III vê-se o sumidouro. Nele podem ser conectados os efluentes domésticos sem sólidos como os advindos do chuveiro, da pia do banheiro, da máquina e do tanque de lavar roupas. A partir deste tanque III, os resíduos líquidos se infiltram no solo.

Figura 1 - Um exemplo de conjunto de fossa

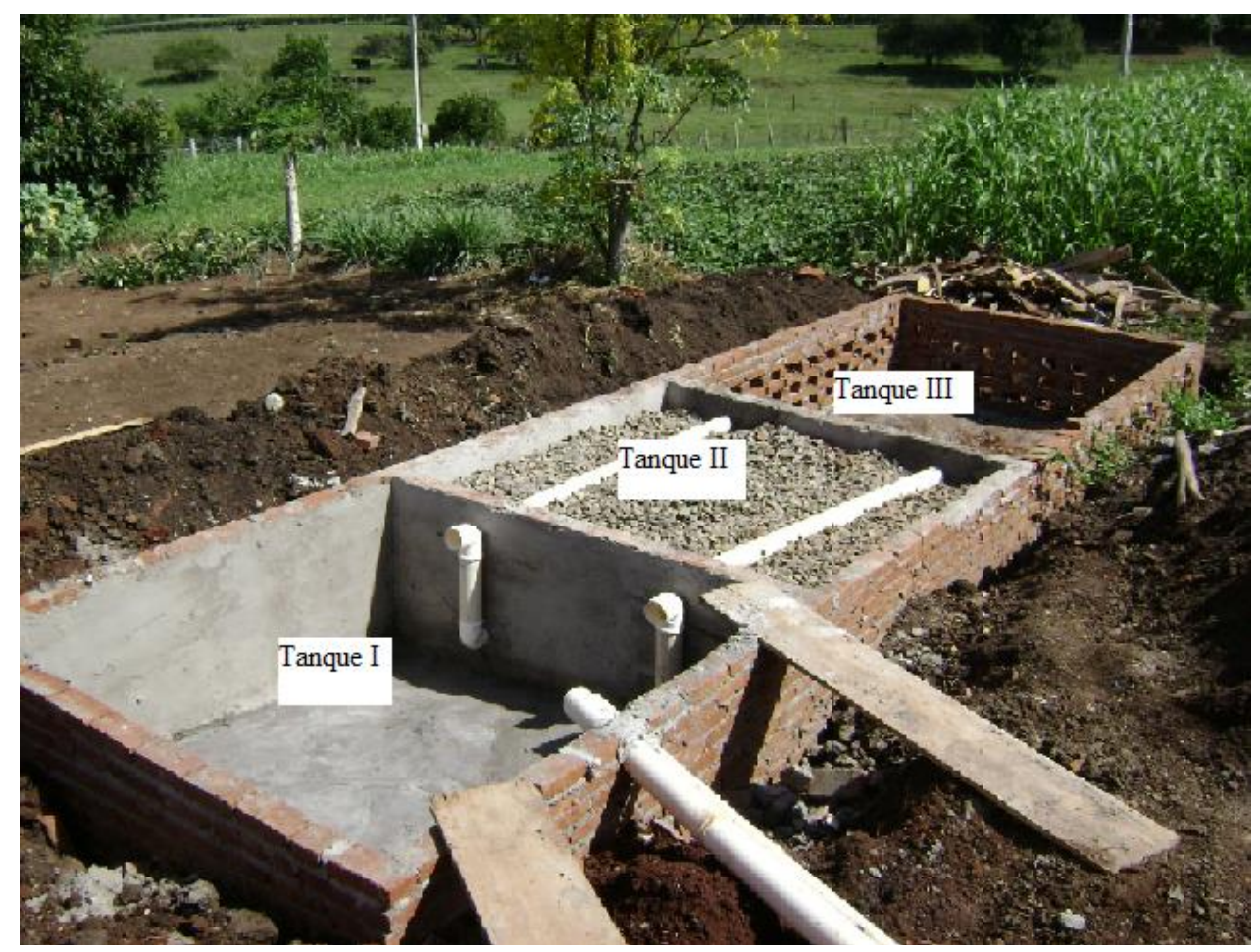

Fonte: Engenheiro colaborador, 2014

No entanto, a Prefeitura normatizou o tamanho das fossas, dos filtros e dos sumidouros em padrões, de acordo com o número de dormitórios e de pessoas que habitam na residência (Quadro 1). Ainda devem ser observadas, na hora da construção, se o padrão de produção de efluentes é médio ou baixo. Habitualmente, segundo informações do engenheiro colaborador, sugere-se adotar o critério de médio padrão para casas maiores. No caso de casas populares, pode-se usar o padrão baixo. 
Quadro 1 - Normativa com número de dormitórios e pessoas e respectivas dimensões dos tanques fossa, filtro e sumidouro

\begin{tabular}{|c|c|c|c|c|c|c|}
\hline \multirow{2}{*}{$\begin{array}{c}\text { Número de } \\
\text { dormitórios }\end{array}$} & \multirow{2}{*}{$\begin{array}{c}\text { Número de } \\
\text { pessoas }\end{array}$} & \multicolumn{2}{|c|}{ Padrão médio (litros) } & \multicolumn{2}{|c|}{ Padrão baixo (litros) } & \multirow{2}{*}{ Sumidouro $\left(\mathrm{m}^{3}\right)$} \\
\cline { 3 - 6 } & 4 & Fossa & Filtro & Fossa & Filtro & \\
\hline 1 & 5 & 1975 & 1250 & 1825 & 1250 & 5,41 \\
\hline 2 & 6 & 2170 & 1250 & 1990 & 1250 & 6,40 \\
\hline 3 & 8 & 2560 & 1660 & - & - & 11,48 \\
\hline 4 & 10 & 2950 & 2080 & - & - & 14,31 \\
\hline 5 & & & & & & \\
\hline
\end{tabular}

Fonte: Engenheiro colaborador, 2014

Sugestões de atividades:

I - Visitar uma obra em andamento e com o auxílio de um engenheiro compreender o que ocorre em cada tanque do sistema de tratamento de efluentes. É relevante que o professor contate o engenheiro previamente e combine com ele e com o proprietário da obra a visita guiada.

II - Após a visita, construir com os alunos um quadro como o a seguir, objetivando calcular o volume de cada tanque do sistema de tratamento de efluentes. Pode-se tomar como exemplo uma casa de dois dormitórios em que residem 5 pessoas. É necessário combinar com os alunos se essa família gera um médio ou baixo padrão de efluentes. As combinações de medidas do comprimento, largura e altura podem ser tantas quantas o professor desejar realizar com sua turma. Poderá também problematizar se é possível construir, por exemplo, uma fossa de exatamente 1975 litros, e se na prática isso ocorre. Desta forma é possível falar em arredondamentos, assunto nem sempre discutido em aula. Neste caso, é importante o professor comentar a necessidade do arredondamento para cima, sob pena de infringir as normas de tratamento de efluentes estabelecidas.

Quadro 2 - Possibilidades do cálculo do volume da fossa

\begin{tabular}{|l|c|c|c|c|}
\hline & $\begin{array}{c}\text { Comprimento } \\
(\mathbf{e m ~ m})\end{array}$ & $\begin{array}{c}\text { Largura } \\
(\mathbf{e m ~ m})\end{array}$ & $\begin{array}{c}\text { Altura } \\
(\mathbf{e m ~ m )}\end{array}$ & $\begin{array}{c}\text { Volume } \\
(\mathbf{e m ~ l i t r o s})\end{array}$ \\
\hline Possibilidade 1 & 1,1 & 1,5 & 1,2 & $1975^{1}$ \\
\hline
\end{tabular}

\footnotetext{
${ }^{1}$ Este volume corresponde a litros. Deve ser convertido para $\mathrm{m}^{3}$. Em adição, cabe mencionar neste caso específico, não é possível obter o número $1,975 \mathrm{~m}^{3}$, multiplicando-se números com uma casa decimal.
} 


\begin{tabular}{|l|c|c|c|c|}
\hline Possibilidade 2 & 0,6 & 3 & 1,1 & 1975 \\
\hline Possibilidade 3 & 0,4 & 1,5 & 3,3 & 1975 \\
\hline$\ldots$ & & & & \\
\hline
\end{tabular}

Fonte: Elaborado pelos autores, 2014

Sugere-se construir outros dois quadros idênticos a este, trocando o tanque I - "fossa" pelos tanques II - "filtro" e, posteriormente tanque III - "sumidouro".

III) Realizar os desenhos ou confeccionar maquetes combinando os três tanques: fossa, filtro e sumidouro. Após discutir as seguintes questões:

a) Os três tanques que compõem o sistema de tratamento de efluentes têm o mesmo volume?

b) É necessário que os três tanques tenham a mesma largura? E o mesmo comprimento? E a mesma altura?

c) Caso tenham alturas diferentes, que implicações isso causa ao construtor? Quando isso poderá ocorrer?

d) Como deve ser dimensionado e/ou desenhado o sistema de tratamento de efluentes caso se deseja que fique semelhante ao da figura 1 ?

e) Quais implicações podem ocorrer se os três tanques tiverem o mesmo volume?

f) E se possuíssem o mesmo volume, qual deveria ser este volume, de acordo com as normas, e por quê?

Sugere-se que esta atividade seja realizada em grupos. Neste caso, o professor pode optar por confeccionar maquetes de tamanhos diferentes (variando o número de dormitórios ou as dimensões dos tanques ou ainda mencionar algumas restrições que o terreno pode ter) para enriquecer a aula. Ao final, os resultados podem ser socializados, com apresentações aos demais grupos, desenvolvendo assim a capacidade de comunicação.

\section{Referências}

BRASIL. Ministério da educação e cultura. Parâmetros curriculares nacionais: Ensino médio. v. 2: Ciência da natureza, matemática e tecnologia. Brasília: MEC, 2006.

NASCIMENTO, Janio Benevides de Souza. O estudo da geometria espacial por meio da construção de sólidos com materiais alternativos. 2014. 125 f. Dissertação (Mestrado) Programa de Pós-Graduação em Ciências Exatas, Centro Universitário UNIVATES, Lajeado, 2014.

RABAIOLII, Leonice Ludwig. Geometria nos anos iniciais: uma proposta de formação de professores em cenários para investigação. 2014. 134 f. Dissertação (Mestrado) - Programa de Pós-Graduação em Ciências Exatas, Centro Universitário UNIVATES, Lajeado, 2014. 
RADAELLI, Rosibel Kunz. A investigação e a ação docente no ensino de geometria em anos iniciais do Ensino Fundamental. 2010. 133 f. Dissertação (Mestrado) - Programa de PósGraduação em Ciências Exatas, Centro Universitário UNIVATES, Lajeado, 2010.

Submetido em setembro de 2014 Aprovado em março de 2015 